\title{
An Activating Janus Kinase-3 Mutation Is Associated with Cytotoxic T Lymphocyte Antigen-4-Dependent Immune Dysregulation Syndrome
}

\section{OPEN ACCESS}

Edited by:

Frédéric Rieux-Laucat, Imagine Institute for Genetic Diseases (INSERM), France

Reviewed by:

Helen C. Su,

National Institute of Allergy and Infectious Diseases $(\mathrm{NIH})$, United

States

Satoshi Okada,

Hiroshima University, Japan

${ }^{*}$ Correspondence: Hermann Eibel

hermann.eibe/@uniklinik-freiburg.de

${ }^{\dagger}$ Present address: Bolan Linghu, Human Genetics \& Computational Biomedicine, Pfizer Worldwide R\&D,

Cambridge, MA, United States

Specialty section: This article was submitted to Primary Immunodeficiencies,

a section of the journal

Frontiers in Immunology

Received: 22 June 2017 Accepted: 04 December 2017 Published: 15 December 2017

Citation: Sic H, Speletas M, Cornacchione V, Seidl M, Beibel M, Linghu B, Yang F, Sevdali E, Germenis AE, Oakeley EJ,

Vangrevelinghe $E$, Sailer $A W$,

Traggiai $E$, Gram $H$ and Eibel $H$ (2017) An Activating Janus Kinase-3 Mutation Is Associated with Cytotoxic

T Lymphocyte Antigen-4-Dependent Immune Dysregulation Syndrome.

Front. Immunol. 8:1824. doi: 10.3389/fimmu.2017.01824
Heiko Sic ${ }^{1}$, Matthaios Speletas², Vanessa Cornacchione', Maximillian Seidli,4, Martin Beibel', Bolan Linghu ${ }^{57}$, Fan Yang ${ }^{5}$, Eirini Sevdali', Anastasios E. Germenis', Edward J. Oakeley', Eric Vangrevelinghe ${ }^{1}$, Andreas W. Sailer ${ }^{1}$, Elisabetta Traggiai', Hermann Gram $^{1}$ and Hermann Eibel ${ }^{4 *}$

${ }^{1}$ Novartis Institute for Biomedical Research, Basel, Switzerland, ${ }^{2}$ Department of Immunology and Histocompatibility, Faculty of Medicine, School of Health Sciences, University of Thessaly, Biopolis, Larissa, Greece, ${ }^{3}$ Institute for Surgical Pathology, University Medical Center Freiburg, Freiburg, Germany, ${ }^{4}$ Center for Chronic Immunodeficiency, University Medical Center Freiburg, Freiburg, Germany, ${ }^{5}$ Novartis Institutes for Biomedical Research, Cambridge, MA, United States

Heterozygous mutations in the cytotoxic T lymphocyte antigen-4 (CTLA-4) are associated with lymphadenopathy, autoimmunity, immune dysregulation, and hypogammaglobulinemia in about $70 \%$ of the carriers. So far, the incomplete penetrance of CTLA-4 haploinsufficiency has been attributed to unknown genetic modifiers, epigenetic changes, or environmental effects. We sought to identify potential genetic modifiers in a family with differential clinical penetrance of CTLA-4 haploinsufficiency. Here, we report on a rare heterozygous gain-of-function mutation in Janus kinase-3 (JAK3) (p.R840C), which is associated with the clinical manifestation of CTLA-4 haploinsufficiency in a patient carrying a novel loss-of-function mutation in CTLA-4 (p.Y139C). While the asymptomatic parents carry either the CTLA-4 mutation or the JAK3 variant, their son has inherited both heterozygous mutations and suffers from hypogammaglobulinemia combined with autoimmunity and lymphoid hyperplasia. Although the patient's lymph node and spleen contained many hyperplastic germinal centers with follicular helper $T\left(T_{F H}\right)$ cells and immunoglobulin (lg) G-positive B cells, plasma cell, and memory B cell development was impaired. CXCR5+PD-1+TIGIT+ $T_{F H}$ cells contributed to a large part of circulating T cells, but they produced only very low amounts of interleukin (IL)-4, IL-10, and IL-21 required for the development of memory B cells and plasma cells. We, therefore, suggest that the combination of the loss-of-function mutation in CTLA-4 with the gain-of-function mutation in JAK3 directs the differentiation of CD4 T cells into dysfunctional $T_{F H}$ cells supporting the development of lymphadenopathy, hypogammaglobulinemia, and immunodeficiency. Thus, the combination of rare genetic heterozygous variants that remain clinically unnoticed individually may lead to T cell hyperactivity, impaired memory B cell, and plasma cell development resulting finally in combined immunodeficiency.

Keywords: cytotoxic T lymphocyte antigen-4, janus kinase-3, haploinsufficiency, immune dysregulation syndrome, $\mathrm{T}$ regulatory cell, $\mathrm{T}$ follicular helper cell, common variable immunodeficiency, immune checkpoint 


\section{INTRODUCTION}

Common variable immunodeficiency (CVID) is the most common primary immunodeficiency. It combines a variety of defects sharing low levels of $\operatorname{IgG}$ and $\operatorname{IgA}(1)$ and although a number of genetic defects has been found to be associated with CVID, the pathogenetic mechanisms of most of the cases remain to be determined $(2,3)$. Paradoxically, a large number of CVID patients suffer from complex autoimmunity and immune dysregulation syndromes (4) and some of these patients have mutations in CTLA4 (5-7). Cytotoxic T lymphocyte antigen-4 (CTLA-4) is expressed by activated $\mathrm{T}$ cells and $\mathrm{T}$ regulatory $\left(\mathrm{T}_{\mathrm{REG}}\right)$ cells and acts as major negative regulator of $\mathrm{T}$ cell responses (8). Thus, the immune dysregulation syndrome is thought to be caused by the accumulation of hyperactive T cells. Genetic inactivation of both Ctla4 alleles in mice causes lymphoproliferation, $\mathrm{T}$ cell infiltration into tissues, and leads to strongly increased serum antibody concentrations whereas inactivation of only one Ctla4 allele (haploinsufficiency) is asymptomatic (9). The situation is more complex in humans because the same heterozygous CTLA4 mutations can be found in patients with immunodysregulation syndrome and in asymptomatic carriers, who may only show subtle immunophenotypic changes like the expansion of FOXP3 $3^{+} \mathrm{T}_{\mathrm{REG}}$ cells (7).

So far, epigenetic, environmental, and genetic factors have been discussed as potential cause for the incomplete penetrance of CTLA-4 mutations $(6,7)$, but it remained unclear how these factors may contribute to the development of a CTLA4-dependent immune dysregulation syndrome.

Here, we report that the combination of a rare heterozygous gain-of-function mutation in the Janus kinase-3 (JAK3) gene with a novel, heterozygous loss-of-function mutation in CTLA-4 severely affects the function of $\mathrm{T}_{\mathrm{FH}}$ cells. The combination of both mutations correlates with immunodeficiency associated with lymphadenopathy, autoimmunity, and hypogammaglobulinemia, whereas carriers of either the CTLA-4 or the JAK3 single mutations are healthy. Residing in the highly conserved ligand binding motif, the CTLA-4 mutation (p.Y139C) abolishes the CD80/CD86 ligand binding of CTLA-4. The activating mutation in JAK3 (R840C, rs200077579) resides in the N-lobe of its kinase domain. JAK3 is mainly expressed in cells of the immune system and associates with the common $\gamma$-chain of cytokine receptors. Binding of the interleukins (IL)-2, IL-7, IL-9, IL-15, and IL-21 to their respective receptors activates JAK3, and by phosphorylating signal transducer and activator of transcription (STAT) transcription factors, the kinase regulates proliferation and cellular differentiation (10). While activating JAK3 mutations have so far been associated with lymphoid hyperplasia and leukemia (11), loss-of-function and hypomorphic mutations lead to a broader variety of clinical phenotypes ranging from lymphoproliferative disorders and milder/ later onset of immunodeficiency to severe combined immunodeficiency $(12,13)$. Activating JAK3 mutations, however, have not yet been reported in the context of primary immunodeficiencies.

\section{MATERIALS AND METHODS}

Additional information on Section "Materials and Methods" including the preparation of DNA libraries, sequencing, and antibodies used in flow cytometry, immunohistochemistry, and western blotting can be found in the Supplementary Material.

\section{Ethics Approval}

Human peripheral blood was obtained from healthy donors and patient. Spleen and lymph node (LN) samples were obtained from patients undergoing splenectomy and LN biopsy. All material was used after written informed consent and in accordance with the approvals 78/2001 and 251/13 of the University Medical Center ethics committee.

\section{Histology}

Formalin-fixed lymphoid tissues embedded in paraffin were cut into $3 \mu \mathrm{m}$ slices and stained after deparaffinization and antigen retrieval with different antibodies as listed in supplementary methods. After applying horse radish peroxidase-coupled secondary antibodies, a brown chromogen reaction developed in the presence of DAB as substrate (Dako Autostainer Link ${ }^{\circledR}$, Dako). Images were taken with a Zeiss Axioobserver using ZEN software. Colors were adjusted with Adobe Photoshop.

\section{Patient}

The 23-year-old male patient had bronchiolitis during infancy and suffered from recurrent upper respiratory tract infections and chronic sinusitis during the last 4 years before the diagnosis of CVID. He was also treated for hypothyroidism the last 3 years before diagnosis. One year before the diagnosis of CVID, splenomegaly, generalized lymphadenopathy in the mediastinum and retroperitoneum, pancytopenia, and severe hypogammaglobulinemia were discovered in the course of gastroenteritis. The patient did not respond to vaccination with pneumococcal polysaccharides. His bone marrow was hypercellular and a stomach biopsy indicated lymphocytic infiltrates. Severe splenomegaly was treated with splenectomy; LN biopsies did not reveal malignancies. The family members are healthy with normal serum immunoglobulin levels except for the Hashimoto's thyroiditis of the mother.

\section{Sequencing Analysis of CTLA-4 and JAK-3}

Genomic DNA was extracted from peripheral blood using the QIAamp DNA Blood Mini Kit (Qiagen, UK). All exons and exon-intron boundaries of CTLA4 and JAK3 genes were amplified using primers shown in Tables $\mathbf{1}$ and $\mathbf{2}$. PCR products were purified (Qiagen) and sequenced using an ABI Prism 310 genetic analyzer (Applied Biosystems, Foster City, CA, USA) and a BigDye Terminator DNA sequencing kit (Applied Biosystems).

\section{Flow Cytometry}

Cells were analyzed by flow cytometry as described before $(14,15)$. FOXP3 expression was tested using either the FOXP3 staining kit (eBioscience) following the manufacturer's instructions, or Lyse/Fix-buffer $\left(\mathrm{BD}, 20 \mathrm{~min}, 37^{\circ} \mathrm{C}\right)$ and Methanol $\left(90 \%, 1 \mathrm{~h},-20^{\circ} \mathrm{C}\right)$ followed by staining for intracellular antigens. Analyses were performed using a Canto II or LSRFortessa (BD) flow cytometer and Diva (BD) and FlowJo software (TreeStar). 
TABLE 1 | The sequences of primers used for the amplification of CTLA4.

\begin{tabular}{lll}
\hline Exon & Primers & Sequence \\
\hline Exon 1 & Forward & 5'-TTCAAgTgCCTTCTgTgTgTg-3' \\
Exon 2 & Reverse & 5'-AATCACTgCC $\tau$ TTgACTgCT-3' \\
& Forward & 5'-gAgAggggAAgggTAAgTg-3' \\
Exon 3 & Reverse & 5'-AgACTgCAATgCAACAggTg-3' \\
& Forward & 5'-TATTggTgggCTACCCATgC-3' \\
Exon 4 & Reverse & 5'-CCCTgCTCAgAAgCACATgA-3' \\
& Forward & 5'-TggCTTCCgTATCCTCAgT-3' \\
& Reverse & 5'-CTCCCTgCCTTTCCTCT-3' \\
\hline
\end{tabular}

TABLE 2 | The sequences of primers used for the amplification of JAK3.

\begin{tabular}{|c|c|c|}
\hline Exon & Primers & Sequence \\
\hline \multirow{2}{*}{$\begin{array}{l}\text { Exon } 2 \text { (including start } \\
\text { codon) }\end{array}$} & Forward & 5'-CATgCССТСССTgCTCAgAA-3 \\
\hline & Reverse & 5'-AAgCCAACCCTgCACACCCTा-3' \\
\hline \multirow[t]{2}{*}{ Exons 3-5 } & Forward & 5'-gATgCTggСАСТСCTgAAggg-3' \\
\hline & Reverse & 5'-ggAgAgggCTgggTTCgTg-3' \\
\hline \multirow[t]{2}{*}{ Exon 6} & Forward & 5'-CTgTggggTCCCTgTCCgA-3' \\
\hline & Reverse & 5'-CgСТСAgCCCAAСССТТСАСТ-3' \\
\hline \multirow[t]{2}{*}{ Exons 7-8 } & Forward & 5'-CggCTTgAAgggTIgAATgg-3' \\
\hline & Reverse & 5'-CTgTgCggCAggTgTgg T-3' \\
\hline \multirow[t]{2}{*}{ Exons 9-10 } & Forward & 5'-ggTgTCACCTggCAAggAT-3' \\
\hline & Reverse & 5'-AACTTCCTgAgCCAACAAATC-3' \\
\hline \multirow[t]{2}{*}{ Exons 11-12 } & Forward & 5'-AAAgCCATgTgCCCTgAAgTCT-3' \\
\hline & Reverse & 5'-CgCCCAggTCCCTgTgTgT-3' \\
\hline \multirow[t]{2}{*}{ Exon 13} & Forward & 5'-CCCgTATCAgAAAATCATggTA-3' \\
\hline & Reverse & 5'-CCTAgACTCCCAACCAATgAAA-3' \\
\hline \multirow[t]{2}{*}{ Exon 14} & Forward & 5'-TTCCAggCATTCCAggCAAAT-3' \\
\hline & Reverse & 5'-САСТСССААТТССТСТТССАСС-3' \\
\hline \multirow[t]{2}{*}{ Exon $15-17$} & Forward & 5'-gTCAggAgTCAgggACgATgCT-3' \\
\hline & Reverse & 5'-ССССТССАACСТCACCAgAC-3' \\
\hline \multirow[t]{2}{*}{ Exons 18-19 } & Forward & 5'-TाTCCTgggACAgAgTgg-3' \\
\hline & Reverse & 5'-CTggCAggAgggTAAgAATgT-3' \\
\hline \multirow[t]{2}{*}{ Exons 20-21 } & Forward & 5'-gTCATTgTTgCgg TाСCCATA-3' \\
\hline & Reverse & 5'-CgggAgACAgAggAgCCAgTg-3' \\
\hline \multirow[t]{2}{*}{ Exons 22-23 } & Forward & 5'-TggAgACgggACTgACCTgCT-3' \\
\hline & Reverse & 5'-CСТCATCggССТCACACTCTA-3' \\
\hline \multirow[t]{2}{*}{ Exon 24} & Forward & 5'-TgggCAACAAgAgCgAAACTT-3' \\
\hline & Reverse & 5'-TाgggCCAggACTCAgAg-3' \\
\hline
\end{tabular}

\section{Cell Based In Vitro Assays}

PBMC and EBV lines were isolated and cultivated and tested for mycoplasma contamination as described before (14). Jurkat and HEK293T/17 cells were obtained from ATCC (Manassas, VA, USA). The acute megakaryoblastic leukemia line M07e was received from DSMZ (Braunschweig, Germany). The cell culture medium for MO7e was supplemented with $10 \mathrm{ng} / \mathrm{ml}$ GM-CSF (R\&D Systems). Dose-dependent proliferation of transduced MO7e cells $\left(5 \times 10^{4}\right.$ cells $\left./ \mathrm{ml}\right)$ was monitored by flow cytometry using 50-300 U/ml IL-2 (Novartis) or $10 \mathrm{ng} / \mathrm{ml}$ GM-CSF.

Activation of T cells was performed with $0.3-1 \times 10^{6} \mathrm{PBMCs}$ by adding anti-CD3 (1 $\mu \mathrm{g} / \mathrm{ml}$, OKT-3, Novartis, Basel, Switzerland) and anti-CD28 (1 $\mu \mathrm{g} / \mathrm{ml}, 15 \mathrm{E} 8$, Novartis $)$ in complete IMDM.

Suppression assays with Jurkat $\mathrm{T}$ cells were performed by mixing $5 \times 10^{4}$ naive CD4 T cells enriched from PBMCs using the EasySep human (naïve) $\mathrm{CD}^{+} \mathrm{T}$ Cell isolation kit (Stemcell Technologies, Vancouver, BC, Canada), with $1 \times 10^{4}$ irradiated (50 Gy) EBV cells, increasing numbers of transduced, YFP sorted, and irradiated (50 Gy) Jurkat cells. The CD4 T cells were activated with anti-CD3 $(1 \mu \mathrm{g} / \mathrm{ml})$, cultured in complete IMDM and pulsed with $1 \mu \mathrm{Ci} /$ well of ${ }^{3} \mathrm{H}$-Thymidine (Perkin Elmer, Norwalk, CT, USA) for $16 \mathrm{~h}$. The incorporation of ${ }^{3} \mathrm{H}$-Thymidine was measured using a $\beta$-plate counter (Wallac).

$\mathrm{T}_{\mathrm{FH}} / \mathrm{B}$ cell co-culture assays were carried out with PBMCs sorted by FACS into $\mathrm{CD} 19^{+} \mathrm{CD} 27^{-} \mathrm{IgA}{ }^{-} \mathrm{IgG}-$ (naïve) B cells and $\mathrm{CD} 4^{+} \mathrm{CD} 8^{-} \mathrm{CD} 45 \mathrm{RA}^{-} \mathrm{CXCR} 5^{+} \mathrm{T}_{\mathrm{FH}}$ cells. The purity of the sorted $\mathrm{B}$ and $\mathrm{T}$ cell subsets was $>95 \% .1 \times 10^{4} \mathrm{~T}_{\mathrm{FH}}$ cells/well were co-cultured with allogeneic B cells (1:1) and activated with endotoxin-reduced Staphylococcal enterotoxin B (SEB, $1 \mu \mathrm{g} /$ $\mathrm{ml}$, Toxin Technology, Sarasota, FL, USA) in complete RPMI 1640 medium complemented with 2-mercaptoethanol and in 384 well plates. After 7 days, supernatants were collected and levels of secreted cytokines were assessed using Meso Scale Discovery (Meso Scale Diagnostics, LLC, MD, USA) following the manufacturer's instructions and an MSD Sector Imager 6000 (MSD).

Intracellular cytokines expressed in activated $\mathrm{T}_{\mathrm{FH}}$ cells from the co-culture assay were detected upon activating the $\mathrm{T}$ cells for $6 \mathrm{~h}$ with $100 \mathrm{ng} / \mathrm{ml}$ PMA (Sigma-Aldrich, St. Louis, MO, USA) and $750 \mathrm{ng} / \mathrm{ml}$ ionomycin (Sigma-Aldrich) in the presence of Brefeldin A (10 mg/ml, Sigma-Aldrich), which was added after $2 \mathrm{~h}$.

$\mathrm{CD}^{1} 9^{+} \mathrm{CD} 27^{-} \operatorname{IgA}{ }^{-} \mathrm{IgG}^{-}$(naïve) B cells were differentiates in vitro into plasmablasts in U96 well plates with $10^{4} /$ well in the presence of CD40L ( $1 \mu \mathrm{g} / \mathrm{ml}$, Novartis), IL-4 (20 ng/ml, R\&D), and IL-21 $(20 \mathrm{ng} / \mathrm{ml}$, Novartis) in complete RPMI 1640 medium supplemented with Glutathione (Sigma-Aldrich), MEM-non essential amino acids (Invitrogen), and insulin-transferrinselenium-x supplement (Invitrogen). Cells and supernatant were collected after 6 days and tested for the expression of surface markers by flow cytometry and for the secretion of IgM and IgG by ELISA as described before (14-16).

\section{Binding Assays}

EBV cells $\left(5 \times 10^{5}\right)$ were incubated with abatacept (orenica, Bristol-Myers Squibb, New York, NY, USA) or recombinant CTLA-4-Ig (Novartis). CD28 on Jurkat cells $\left(5 \times 10^{5}\right)$ was first blocked by treatment with anti-CD28 (CD28.2, BD) followed by incubation with recombinant CD80/CD86 (R\&D). The cells were then stained with FITC-coupled anti-human IgG (eBioscience) and analyzed by flow cytometry.

\section{SDS-PAGE and Western Blotting}

Western blotting was performed as described before (15). Transduced MO7e cells were washed twice with FCS-free medium and incubated overnight in IMDM, $0.1 \%$ FCS. Then, $7 \times 10^{5}$ cells were washed with ice-cold PBS, lysed with NuPAGE LDS sample buffer $\left(5 \times 10^{6} \mathrm{cells} / \mathrm{ml}\right)$, vortexed, and heated to $70^{\circ} \mathrm{C}$ for $10 \mathrm{~min}$. $20 \mu \mathrm{l} /$ sample were separated by $4-12 \%$ PAGE and transferred to PVDF membranes using the Trans-Blot turbo system (Bio-Rad, CA, USA).

\section{Expression Plasmids}

Synthetic 738 bp DNA fragments encoding either wild-type or Y139C mutant CTLA-4 were obtained from Integrated 
DNA Technologies (Leuven, Belgium). The ssBMS-CTLA4-Ig expression plasmid and the pcDNA3.1-based plasmids containing JAK3-WT or JAK3-A572V were obtained from C. Haan (17). CTLA-4-Y139C and JAK3-R840C were generated by using the QuikChange XL site-directed mutagenesis kit (Agilent Technologies) and following oligonucleotides: CTLA-4 (full-length)

\section{f-5' -CATGTACCCACCGCCATGCTACCTGGGCATAG-3' and \\ r-5'-CTATGCCCAGGTAGCATGGCGGTGGGTACATG-3'; \\ CTLA-4 (ssBMS) \\ f-5'-GATGTACCCCCCTCCCTGCTACCTGGGCATCG-3', r-5'CGATGCCCAGGTAGCAGGGAGGGGGGTACATC-3'; JAK3: \\ f-5' ${ }^{\prime}$-CGTGGAGCTGTGCTGCTATGACCCGCTAGG-3' and r-5' - CCTAGCGGGTCATAGCAGCACAGCTCCACG-3'.}

The lentiviral expression vectors pNL-CEF-eGFP and pNLCEF-YFP/CFP were described before $(14,16)$. CTLA- 4 coding regions were cloned into $\mathrm{pNL}-\mathrm{CEF}-\mathrm{YFP} / \mathrm{CFP}$ by replacing a 702 bp fragment with the corresponding synthetic DNA fragments. An internal ribosomal entry site (IRES) was cloned from pIRES2-eGFP (Clontech Laboratories, Mountain View, CA, USA) into pNL-CEF-eGFP generating the pNL-CEF-IRES-eGFP backbone. JAK3 coding regions were then sub-cloned into pNLCEF-IRES-eGFP. Enzymes used for cloning were from New England Biolabs (Ipswich, MA, USA), Roche (Basel, Switzerland) or from Fermentas (Vilnius, Lithuania). All constructs were verified by Sanger sequencing.

\section{Transfections and Infections}

Lentiviral particles were generated using a standard protocol (14) upon transfection of HEK293T/17 cells with pCDNLBH* and pVSV-G, and the pNL-based constructs. Supernatants were collected 2 days after transfection, filtered $(0.45 \mu \mathrm{m}$, Pall Corporation, NY, USA) and $1 \mathrm{ml}$ were used to spin-infect $5 \times 10^{5}$ Jurkat, MO7e cells, or anti-CD3 $(1 \mu \mathrm{g} / \mathrm{ml})$ and anti-CD28 $(1 \mu \mathrm{g} / \mathrm{ml})$ activated PBMCs or $\mathrm{CD}^{+} \mathrm{T}$ cells.

\section{Recombinant Protein Production}

Recombinant CTLA-4-Ig was produced by growing suspensionadapted HKB11 cells (Human Embryonic Kidney cells fused with Burkitt's lymphoma cells, Bayer) transfected with expression plasmids in serum-free culture medium M11V3 in a WAVE bioreactor. Cultures were supplemented with an equal volume of DM133 enriched with Yeastolate (2 g/l) (Irvine Scientific, Santa Ana, CA, USA) and incubated for 3-8 days.

Supernatants were filtered through a dead end filter (Millistak + Pod Disposable Depth Filter System Merck Millipore, Darmstadt, Germany), sterilized (0.22 $\mu \mathrm{m}$ stericup filter, Millipore), and concentrated (Cross flow filter Hemoflow, $10 \mathrm{kDa}$, Fresenius, Bad Homburg, Germany). Proteins were purified by MabSelect affinity chromatography (GE Heathcare, Chicago, IL, USA), eluted (50 mM Tris, $90 \mathrm{mM} \mathrm{NaCl} \mathrm{pH} \mathrm{3.2)}$ and immediately neutralized to $\mathrm{pH} 7.3$ by slow addition of $1 \mathrm{M}$ Tris $\mathrm{pH} 10$.

\section{Protein Modeling}

The modeling of the JAK3 JH2-JH1 homology domain was done using TYK2 (PDB 4OLI) (11) as template and Prime 4.2 software of Schrödinger Release 2015-4 (Schrödinger, New York, NY, USA). Images of the CTLA-4/CD80 structure [PDB 1I8L (18)] and the JAK3 model were generated with ICM (Molsoft LLC, San Diego, CA, USA).

\section{Statistical Analysis}

Significant differences were analyzed by unpaired Student's $t$-test, by Tukey's or Holm-Sidak's (one-way ANOVA) or Dunnett's or Holm-Sidak's (one-way ANOVA) multiple comparisons test using GraphPad Prism software (GraphPad). Values of $P \leq 0.05$ were considered significant.

\section{RESULTS}

\section{A Novel Loss-of-Function Mutation in CTLA4}

Analyzing the exomes of a primary antibody deficiency cohort of 37 individuals from 9 families, we identified in one family a novel heterozygous missense mutation (p.Y139C) in the CTLA4 gene (Figure 1A). The mutation is shared by the patient (A.II.1) and the father (A.I.1). While the patient is diagnosed with hypogammaglobulinemia, signs of autoimmunity and severe lymphoproliferation which required splenectomy, the father is asymptomatic and has normal IgG and IgA levels (Table 3). Since the p.Y139C CTLA-4 variant has not been documented before and because it is not shared by any of A.I.1 siblings, it most likely has arisen de novo in A.I.1. The mutation is localized in the evolutionary highly conserved ligand-binding motif (MYPPPY) of CTLA-4 and changes the second tyrosine to cysteine (Figure 1B). A very similar change (Y139A) introduced by site-directed mutagenesis was shown to abolish CTLA-4 binding to CD80 and CD86 $(19,20)$.

To address the question if the Y139C mutation changes the surface expression of CTLA-4, we constructed lentiviral expression vectors for wild-type (WT) and mutant (Y139Y) CTLA-4 expressing fusion proteins of CTLA-4 linked at the C-terminal end to CFP and YFP.

Co-expression of wild-type and mutant forms revealed that the mutant did not interfere with the expression of the wild-type form. However, comparing the expression of both fusion proteins, we found that the Y139C mutant was expressed at lower levels on the cell surface (Figure 1C) although total expression levels of CTLA-4-YFP and CTLA-4-Y139Y-YFP were very similar (Figure $\mathrm{S} 1$ in Supplementary Material).

In contrast to CTLA-4-WT, CTLA-4-Y139C did not bind recombinant soluble $\mathrm{CD} 80$ or CD86. Vice versa, recombinant CTLA-4-Y139C did not bind to CD80/CD86 expressed on an EBV immortalized B cell line (Figure 1D; Figure S2 in Supplementary Material). In an in vitro suppression assay, Jurkat $\mathrm{T}$ cells expressing the CTLA-4-Y139C variant did not suppress co-stimulation-dependent proliferation of naïve $\mathrm{CD}^{+} \mathrm{T}$ cells (Figure 1E). Analyzing the $\mathrm{T}_{\mathrm{REG}}$ cells of the patient, we found that they did not suppress the proliferation of activated responder 


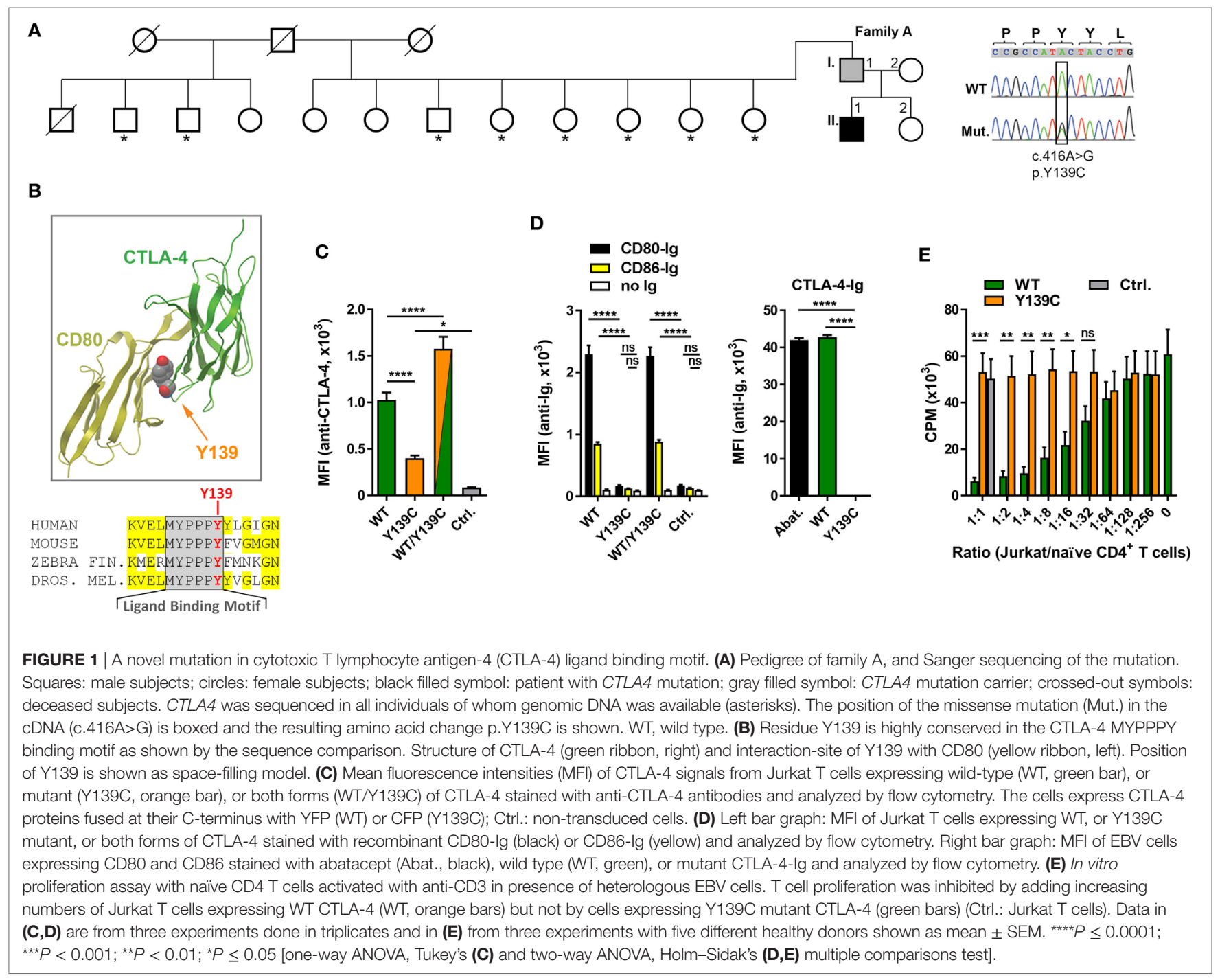

$\mathrm{T}$ cells in vitro, whereas the $\mathrm{T}_{\mathrm{REG}}$ cells of the carrier A.I.1 still showed suppressor activity under the assay conditions (Figure S3 in Supplementary Material). We, therefore, conclude that CTLA-4-Y139C is a loss-of-function mutation with incomplete penetrance in vivo and similar to other previously reported mutations inactivating CTLA-4 (5-7).

The percentage of $\mathrm{CD} 45 \mathrm{RA}^{+} \mathrm{CCR} 7^{+}$naïve $\mathrm{T}$ cells was reduced in the patient A.II.1 but not the healthy carrier A.I.1, while the proportion of $\mathrm{CD}^{2} 5 \mathrm{RA}^{-} \mathrm{CCR} 7^{-} \mathrm{CD}^{+}$effector memory $\mathrm{T}$ cells ( $\mathrm{T}_{\mathrm{EM}}$ cells) and of CD45RA ${ }^{+} \mathrm{CCR} 7^{-} \mathrm{CD}^{+}$effector memory $\mathrm{T}$ cells ( $\mathrm{T}_{\text {EMRA }}$ cells) was markedly higher than in controls (Figure 2A). Similar changes in the $\mathrm{T}$ cell compartment have been reported previously for other CTLA-4 haploinsufficiency patients $(6,7)$, including an increased percentage of $\mathrm{CD}^{+} \mathrm{FOXP}^{+} \mathrm{T}$ cells, which was higher in patient A.II.1 than in the carrier A.I.1 (Figure 2B). In contrast to the increase in $\mathrm{CD}^{+} \mathrm{FOXP}^{+} \mathrm{T}$ cells frequency, the expression levels of intracellular FOXP3 and CTLA-4 in $\mathrm{FOXP}^{+} \mathrm{CD}^{2} 5^{+} \mathrm{T}_{\mathrm{REG}}$ cells were comparable among all family members and healthy donors (Figure 2C). Therefore, we conclude that CTLA-4 haploinsufficiency in A.I.1 and A.II.1 results-like the recently described CTLA-4-P137R mutation (21)-from a functional defect of CTLA-4 and not from impaired expression of CTLA- 4 by $\mathrm{T}_{\mathrm{REG}}$ cells.

\section{A Rare Gain-of-Function Mutation in JAK3}

Since the heterozygous CTLA4 mutation was found in the patient and in the healthy carrier, we assumed that the patient might have inherited another genetic defect with incomplete penetrance from his mother (A.I.2). This genetic defect would enhance the consequences of CTLA- 4 haploinsufficiency and lead to an overt immune dysregulation syndrome. Therefore, we searched for rare genetic variants in the exome of patient A.II.1, which were inherited from the mother A.I.2, but not from the father A.I.1. A rare, heterozygous missense JAK3 mutation (p.R840C, rs200077579) fulfilled these criteria. Among Europeans, missense mutation has been found in $1 / 3335$ individuals $(22,23)$. Since the $\mathrm{R} 840$ residue is located in the N-lobe of the JH1 domain (24) close to a loop of a beta-sheet motif, which covers the ATP binding site, the R840C 


\begin{tabular}{|c|c|c|c|c|c|c|c|c|c|c|c|c|}
\hline & \multirow{2}{*}{\multicolumn{2}{|c|}{ Normal values }} & \multirow{2}{*}{\multicolumn{2}{|c|}{$\begin{array}{c}\text { A.I.1 (father) } \\
1-2015\end{array}$}} & \multicolumn{8}{|c|}{ A.Il.1 (patient) } \\
\hline & & & & & \multicolumn{2}{|c|}{$7-2011$} & \multicolumn{2}{|c|}{$3-2012^{a}$} & \multicolumn{2}{|c|}{$7-2013$} & \multicolumn{2}{|c|}{$7-2015$} \\
\hline & Cells/ $\mu \mathrm{L}$ & (\%) & Cells $/ \mu \mathrm{L}$ & $(\%)$ & 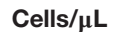 & (\%) & Cells $/ \mu \mathrm{L}$ & $(\%)$ & Cells/ $\mu \mathrm{L}$ & (\%) & 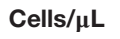 & $(\%)$ \\
\hline WBC & $4,500-10,500$ & & 9,300 & & 3,600 & & 7,300 & & 11,600 & & 13,700 & \\
\hline Neutrophils & 1,500-6,500 & & 5,840 & & 1,569 & & 4,416 & & 6,610 & & 8,640 & \\
\hline Monocytes & $200-1,000$ & & 530 & & 324 & & 613 & & 1,260 & & 1,099 & \\
\hline Lymphocytes & $1,200-3,800$ & & 2,511 & & 1,707 & & 2,270 & & 2,571 & & 1,916 & \\
\hline $\mathrm{CD}^{+}$ & $700-2,100$ & (55-83) & 1,404 & (55.9) & 1,512 & (88.6) & 1,580 & (69.6) & 1,923 & $(74.8)$ & 1,412 & (73.7) \\
\hline $\mathrm{CD}^{+}{ }^{+} \mathrm{CD} 4^{+}$ & $300-1,400$ & $(28-57)$ & 467 & (33.3) & 1,123 & (74.3) & 980 & (62) & 1,053 & $(55)$ & 747 & (39) \\
\hline $\mathrm{CD}^{+}{ }^{+} \mathrm{CD} 8^{+}$ & 200-900 & $(10-39)$ & 236 & $(16.8)$ & 316 & (20.9) & 515 & (32.6) & 638 & (33.3) & 619 & (32.3) \\
\hline CD4/CD8 & $1-3.6$ & & 1.98 & & 3.6 & & 1.9 & & 1.65 & & 1.21 & \\
\hline $\mathrm{CD} 6^{+} \mathrm{CD}^{-} 6^{+}$ & $90-600$ & $(7-31)$ & 856 & (34.1) & 56 & (33.3) & 547 & $(24.1)$ & 177 & $(6.9)$ & 98 & (5.1) \\
\hline CD19+ & $100-500$ & $(6-19)$ & 216 & $(8.6)$ & 137 & (8) & 143 & $(6.3)$ & 468 & $(18.2)$ & 356 & (18.6) \\
\hline Immunoglobulin (mg/dl) & A.I.1 (father) & A.Il.1 (patient) & & & & & & & & & & \\
\hline $\operatorname{lgG}(847-1,690)$ & 1,120 & 387 & & & & & & & & & & \\
\hline $\operatorname{lgM}(64-249)$ & 102 & 57.9 & & & & & & & & & & \\
\hline $\lg A(99-300)$ & 266 & 47.5 & & & & & & & & & & \\
\hline $\mathrm{RF}$ & Negative & Negative & & & & & & & & & & \\
\hline ANA & Negative & Negative & & & & & & & & & & \\
\hline
\end{tabular}

aPatient already subjected to splenectomy and receiving Ig replacement bold out of normal range.

mutation might change the conformation of the N-lobe and its ability to interact with the pseudokinase domain (Figures 3A,B). This would change the kinase function and the activity of JAK3. As a consequence, cells expressing R840C JAK3 would respond differently to ILs like IL-2, which bind to receptors containing the JAK3-associated cytokine receptor common $\gamma$-chain.

Using different readout systems, we, therefore, tested the activity of the R840C variant in response to IL-2. First, we transduced the IL-2 indicator cell line MO7e with lentiviral expression vectors encoding the wild-type form of JAK3, the constitutiveactive, and lymphoma-associated variant JAK3-A572V (17), or the JAK3-R840C variant, and analyzed IL-2-dependent growth at increasing IL-2 concentrations (Figure 3C). Different from wildtype JAK3, the constitutive-active A572V JAK3 and, to a lesser extent, the JAK3-R840C mutant supported IL-2-independent growth as well as higher growth rates at low IL-2 concentrations (Figure 3C). Similar to MO7e cells, expression of the JAK3 variant $\mathrm{R} 840 \mathrm{C}$ also enhanced the growth of lentivirally transduced primary human $\mathrm{CD}^{+} \mathrm{T}$ cells (Figure 3D). Next, we assessed the phosphorylation of STAT5, the direct target of JAK3 kinase activity in MO7e (Figure 3E) and primary human $\mathrm{CD}^{+} \mathrm{T}$ cells (Figure 3F) transduced either with wild-type JAK3 or the gain-of function mutants of JAK3. As expected, basal level and IL-2induced STAT5 phosphorylation was higher in cells expressing the JAK3-R840C or the constitutive active A572V variant than in cells expressing WT JAK3 (Figures 3E,F). Thus, the R840C missense mutation results in a gain-of-function variant of JAK3 as it increases the kinase activity of the enzyme.

Compared to the constitutive-active and lymphoma associated JAK3-A572V variant, the R840C variant has lower intrinsic JAK3 kinase activity, which explains why it has not yet been reported in conjunction with $\mathrm{T}$ cell hyperplasia, and why the carrier A.I.2 does not show signs of hematological malignancies.

\section{Germinal Center Hyperplasia and Changed Architecture of LNs and Spleen}

Our data revealed that the patient's hypogammaglobulinemia is associated with CTLA-4 haploinsufficiency, increased JAK3 activity, and increased percentages of circulating $\mathrm{CD}^{+}$and $\mathrm{CD}^{+}$effector memory $\mathrm{T}$ cells. Since IgG and IgA-secreting long-lived plasma cells develop in germinal centers, we assumed that the immunological changes described above correlate with changes in the architecture of germinal centers. To this end, we analyzed paraffin-embedded tissue sections of spleen and LN samples of the patient using a set of markers defining $\mathrm{T}$ cell and B cell subsets. LN sections showed many follicles with very large, irregularly shaped BCL6-positive germinal centers (GC) containing many ICOS and PD-1 positive $\mathrm{T}_{\mathrm{FH}}$ cells (Figure 4A). In spite of the GC hyperplasia, the typical polarization was clearly detected with distinct dark zones containing proliferating $\mathrm{Ki}^{+} 7^{+}$ cells, and light zones containing IRF4 ${ }^{+}$GC B cells. Although the GCs contained IgG $^{+}$class-switched plasmablasts as well as BLIMP-1 expressing plasma cell precursors (Figure 4A), mature $\mathrm{CD}_{138^{+}}$plasma cells were not detected in GCs and found only in very small numbers in extrafollicular areas. Staining of B cells for IgD, IgM, and CD20 in spleen sections (Figure 4B) revealed a "follicle in the follicle-like" architecture in both LN and spleen. These structures also contained large $\mathrm{ICOS}^{+}$and $\mathrm{PD}-1^{+}$germinal centers with $\mathrm{CD} 25^{+}$cells, which include activated and $\mathrm{T}_{\mathrm{REG}}$ cells. Therefore, the development of GC B cells into plasma cells seems to proceed up to the stage of plasmablasts within GCs but appears not to continue beyond this stage because $\mathrm{CD} 138^{+}$extrafollicular plasma cells were almost absent. Similar to the differentiation into plasma cells, the development of switched memory B cells was defective, as memory B cells were not detected in circulation (see below). 

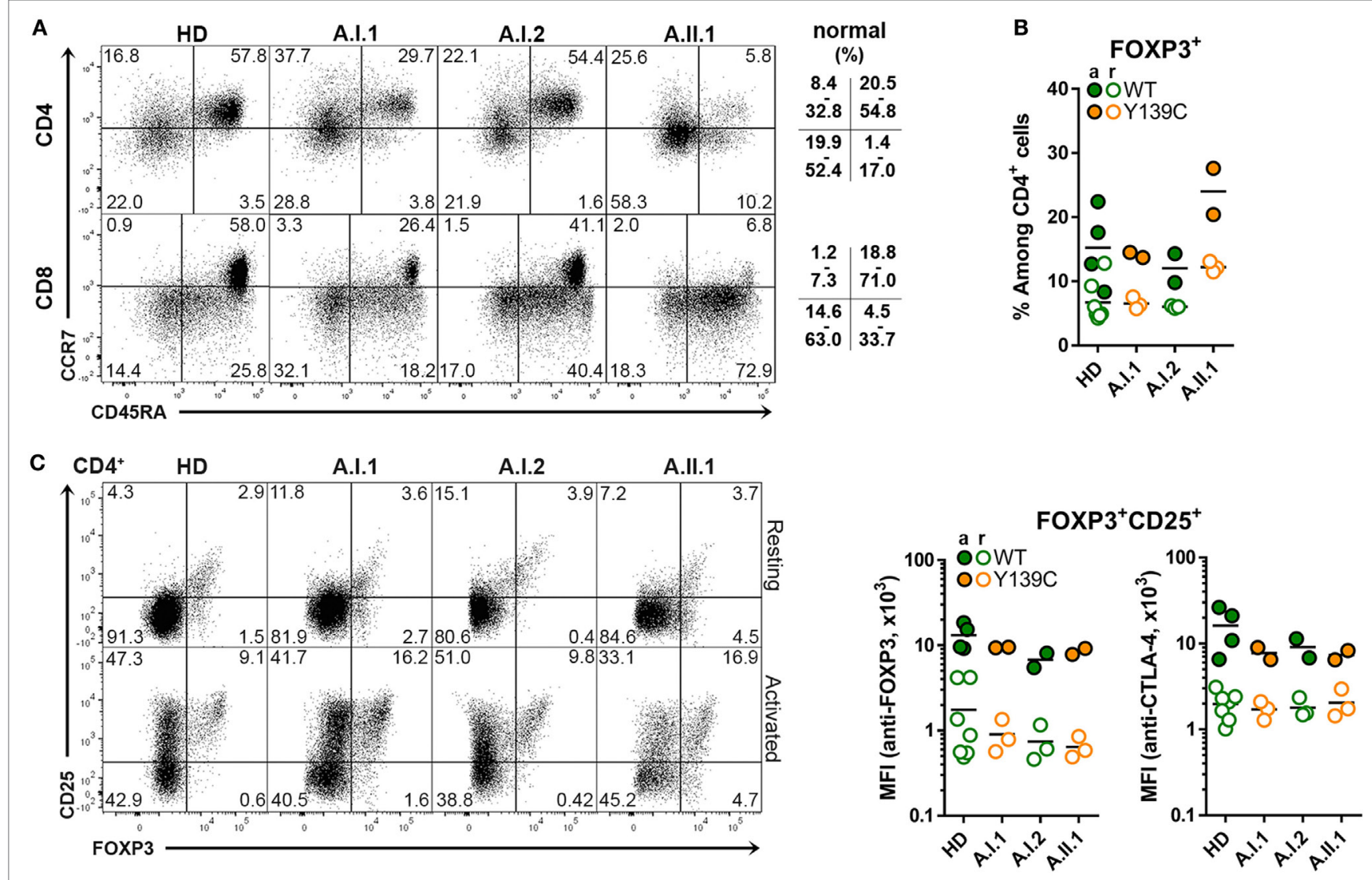

FIGURE 2 | Cytotoxic T Iymphocyte antigen-4 (CTLA-4) expression in TREG cells. (A) Representative flow cytometry plots of PBMCs stained with anti-CD3, CD4, CD8 CD45RA, and CCR7 antibodies. The plots show the population frequencies of naïve T cells (upper right), central memory $T$ cells (upper left), effector memory $\mathrm{T}$ cells (bottom left) and CD45RA+ effector memory $\mathrm{T}$ cells (bottom right) cells in the $\mathrm{CD} 3^{+} \mathrm{CD} 4^{+}$or $\mathrm{CD} 3^{+} \mathrm{CD} 8^{+} \mathrm{T}$ cell subsets isolated from a healthy donors (HD), family members A.I1.1, A.I.2, and patient A.II.1. The normal range of each subset is indicated. (B) Percentage of FOXP3+ CD4+ $\mathrm{T}_{\mathrm{REG}}$ cells from HD and from family A members A.I.1, A.I.2, A.Il.1 (patient). (C) Representative flow cytometry plots showing $T_{\text {REG }}$ cells of resting and anti-CD3 + anti-CD28-activated CD4+ T cells stained with anti-CD25 and anti-FOXP3 antibodies. The bar graph displays the mean fluorescence intensity of FOXP3 and of CD25 signals of resting (open circles) and activated (filled circles) CD4+ T cells isolated from HD and family A members A.I.1, A.I.2, and A.Il.1 (patient). Horizontal lines represent mean values. The dots in $(\mathbf{B}, \mathbf{C})$ represent the samples of individual HD or family member analyzed in replicates in repeated experiments carried out after different visits.

\section{High Frequency of PD-1 and TIGIT Expressing Circulating $\mathrm{T}_{\mathrm{FH}}$ Cells}

Circulating $\mathrm{PD}-1^{+} \mathrm{CD} 4^{+} \mathrm{CXCR} 5^{+} \mathrm{T}$ cells were increased in frequency with a large proportion of cells expressing ICOS (Figure 5A). Moreover, CXCR $5^{+} \mathrm{PD}-1^{+} \mathrm{T}$ cells of A.II.1 expressed more PD- 1 than the cells of all controls (Figure 5A). Most of these $\mathrm{CXCR}^{+} \mathrm{T}_{\mathrm{FH}}$ cells also expressed TIGIT (Figure 5B), a "checkpoint" molecule expressed by circulating $\mathrm{T}_{\mathrm{FH}}$ cells. This subset was reported to have an increased capacity in supporting B cell proliferation and class switch recombination (25). In the patient, all CXCR5 ${ }^{+}$TIGIT $^{+} \mathrm{T}$ cells were expressing PD-1 (Figure 5B). A slight, but significant increase of these activation markers was also observed on $\mathrm{CD} 4^{+} \mathrm{T}$ cells of the non-symptomatic CTLA-4 Y139C carrier A.I.1 compared to controls (Figure 5C). Since the phenotypic analysis of another patient with CTLA-4 haploinsufficiency (p.Y89X) but wild-type-JAK3 identified in this study revealed normal expression levels of PD-1 and TIGIT in circulating $\mathrm{CD}^{+} \mathrm{T}$ cells (Figure 5D), we tested if activation of the
JAK3 pathway as found for the R840C mutation upregulates PD-1 and TIGIT expression in $\mathrm{CD}^{+} \mathrm{T}$ cells. To this end, we activated $\mathrm{CD}^{+} \mathrm{T}$ cells from healthy controls with IL-7 and IL-15 in the presence and absence of the JAK inhibitor tofacitinib. While activation with IL-7 and IL-15 lead to an increase in PD-1 and TIGIT surface expression, the upregulation was blocked by tofacitinib (Figure 5E). This suggests that the enhanced activity of the JAK3R840C variant might contribute to the unusual PD- $1^{+}$TIGIT $^{+} \mathrm{T}_{\mathrm{FH}}$ cell phenotype of the patient.

\section{Reduced Cytokine Secretion Impairs $\mathrm{T}_{\mathrm{FH}}$ Cell Function}

Extrapolating from the observations made in CTLA-4 deficient mice (9), it would have been expected that the increased proportion of $\mathrm{T}_{\mathrm{FH}}$ cells in patient A.II.1 enhances plasma cell development. However, consistent with the patient's hypogammaglobulinemia, immunohistochemical analysis of LN sections revealed very few extrafollicular $\mathrm{CD}_{138^{+}}$plasma cells although $\mathrm{IgG}^{+}$cells were 


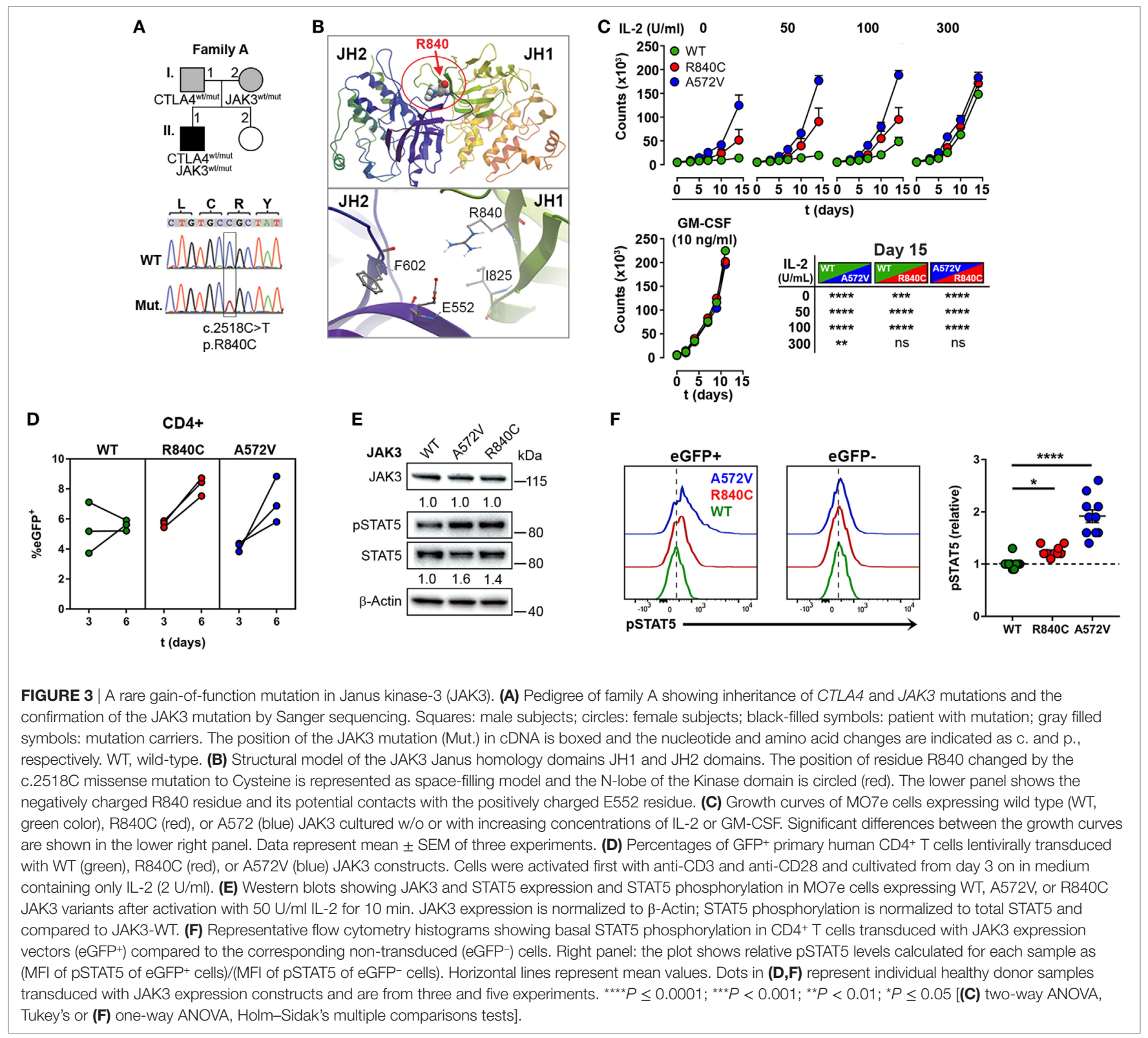

detectable within the GCs (Figure 4A). Numbers of circulating $\mathrm{B}$ cells were normal but lacked a CD $27^{+}$memory B cell compartment (Figure 6A). Interestingly, B cell numbers increased and remained at relatively high counts after splenectomy without being enriched for $\mathrm{CD} 10^{+} \mathrm{CD} 38^{+}$transitional B cells (Figures 6A,B). In addition, the compartment of circulating $B$ cells contained mainly $\mathrm{CD} 21^{\text {lo }}$ cells, which are likely to represent recently activated cells that respond poorly to new stimulating signals (Figure 6C) (26). An increase in CD2 $1^{\text {lo }} \mathrm{B}$ cells observed in HIV patients (27) is mainly attributed to the expansion of dysfunctional T-helper cells (28). To discriminate between intrinsic B cell defects impairing the differentiation into IgG switched memory B cells and plasma cells and disturbed $\mathrm{T}_{\mathrm{FH}}$ cell function, we next tested in vitro differentiation of $\mathrm{B}$ cells and cytokine secretion by activated $\mathrm{T}$ cells.
The intrinsic B cell defect was excluded as $\mathrm{CD}^{2} 7^{-} \mathrm{IgG}^{-}{ }^{-} \mathrm{IgA}^{-}$ sorted (naïve) B cells of A.II.1 developed in vitro into class-switched $\mathrm{IgG}^{+}$(Figure 6D) and antibody secreting cells (Figure 6E) similar to naïve $\mathrm{B}$ cells from healthy controls. Next, we tested $\mathrm{T}_{\mathrm{FH}}$ cells function by monitoring cytokine production. The frequency of IL-21 and IL-4-expressing $\mathrm{T}_{\mathrm{FH}}$ cells from A.II.1 and the amount of secreted IL-4, IL-6, and IL-10 were significantly lower, while other cytokines appeared normal compared to $\mathrm{T}_{\mathrm{FH}}$ cells from HDs (Figure 6F). Thus, $\mathrm{T}_{\mathrm{FH}}$ cells from A.II.1 are deficient in providing the key cytokines IL-21 and IL-4, which are crucial for the differentiation, expansion, class-switch recombination, and survival of antigen-selected B cells in the GC $(29,30)$. The molecular cause for the selectively impaired production of IL-21, IL-4, and IL-10 is not understood yet, but the high expression of 

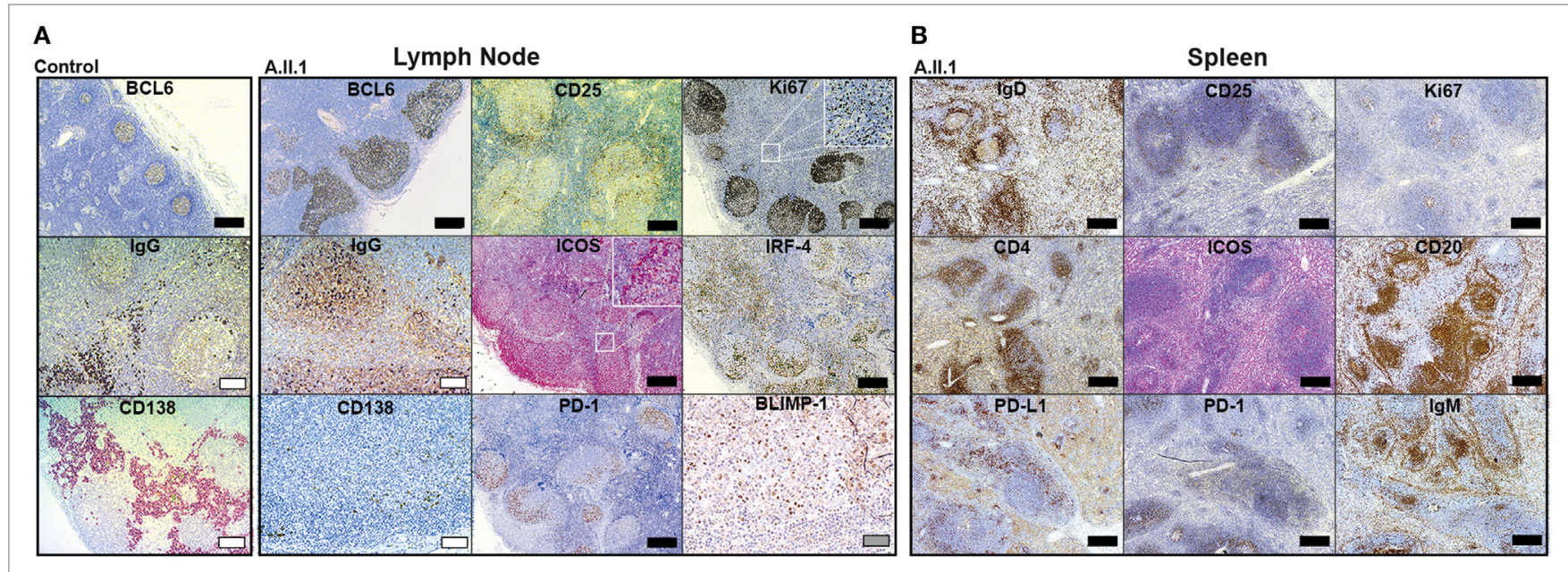

FIGURE 4 | Immunohistochemistry of patient lymph node (LN) and spleen samples. Representative images of immunoperoxidase stainings of LN (A) and spleen (B) tissues. Large germinal centers were identified by staining for BCL6 in the patient's LN and compared to LN of a healthy control (control). Additional GC markers, such as IgG defining immunoglobulin class-switched plasmablasts, Ki67 for labeling centroblasts, ICOS and PD-1 for follicular T-helper cells (TFH cells), IRF-4 marking plasma blasts, and BLIMP-1 for GC B cells poised to develop into plasma cell are shown in (A). Additional staining of IgD (resting follicular B cells), IgM (follicular and marginal zone B cells), CD20 (B cells), CD4 (T-helper cells), Ki67 (proliferating cells), ICOS and PD-1 (TFH Cells), PD-L1 (B cells and DCs), and CD25 (activated T cells and $T_{R E G}$ cells) in the spleen are shown in (B). Mature plasma cells were identified by staining for CD138 in (A). Scale bars; black, 500 $\mu$ m; white, $100 \mu \mathrm{m}$; gray, $50 \mu \mathrm{m}$.

PD-1, a negative regulator of $\mathrm{T}$ cell activation (31) might interfere with cytokine secretion and contribute to the immunodeficiency.

\section{DISCUSSION}

In our study, we found a novel heterozygous missense mutation in one allele of the CTLA-4 gene causing a non-synonymous amino acid exchange (p.Y139C) in the MYPPPY ligandbinding motif of the CTLA-4 protein. The mutation completely abrogates the binding of CTLA- 4 to CD80 and CD86 and the ability of CTLA-4 Y139C expressing cells to suppress T cell proliferation in vitro. However, the patient's father carries the same CTLA4 mutation without showing any clinical symptoms. Therefore, lymphadenopathy, splenomegaly, low IgG concentrations, the absence of memory $B$ cells, and the increase of the $\mathrm{CD} 21^{\text {lo }} \mathrm{B}$ cell subset found in the patient resemble an immune dysregulation syndrome resulting from CTLA-4 haploinsufficiency with incomplete penetrance, as it has been described before for other heterozygous mutations in CTLA4 $(5-7,21$, 32-34). Since the same CTLA4 mutations are found in patients and in healthy carriers, additional, potentially genetic factors were postulated to contribute to the pathologic manifestations of the CTLA-4 haploinsufficiency-associated immunodysregulation syndrome (32-34).

To explain the incomplete penetrance of the heterozygous CTLA-4 mutation found in this family, we searched the exome of the mother (A.I.2) for heterozygous mutations with the potential of changing lymphocyte function, which were inherited by the patient (A.II.1) but absent in the exome of the father (A.I.1). Out of a set of 25 candidate genes, we identified a heterozygous missense mutation in JAK3 changing the arginine residue R840 to cysteine. This residue forms a central part of the JAK3 protein, which is conserved in evolution from fish to humans. Located in a region sharing high homology to the JH2-JH1 domains of TYK2 (11), the R840 residue of JAK3 lies at the interface between the kinase domain and the pseudokinase JH2 domain. At this position, the arginine residue can form van-der-Waals contacts with I825 and contribute to the stabilization of the JH2-JH1 complex through $\mathrm{H}$-bond interactions with F602/E552 or by ionic interactions with the side-chain of E552. The JAK3-R840C variant has been reported to have intrinsic kinase activity, as it was found to overcome resistance to a JAK1 inhibitor in an in vitro culture system (35). Interestingly, the gain-of-function mutation R867Q of JAK2 (36) is located at a position corresponding to amino acid 840 in JAK3 (11), suggesting a critical role of these residues in controlling the activity of JAK proteins. Similar to the acute myeloid leukemia associated gain-of-function variant JAK3A572V (37), expression of the JAK3-R840C variant enhanced the proliferation of transduced primary $\mathrm{T}$ cells and of cell lines in vitro. Although the in vitro system does not fully reflect the more complex in vivo situation, it provides experimental evidence for a potential contribution of the JAK3-R840C variant to the pronounced lymphoproliferation in A.II.1 with underlying CTLA-4 syndrome. The clinically unremarkable phenotype of the mother, who is a JAK3 R840C carrier, suggests that the R840C missense mutation still allows normal $\mathrm{T}$ cell homeostasis in the presence of normal CTLA-4 function. The fact that the JAK3-R840C variant has so far been detected only in an in vitro selection system (35), but never in conjunction with malignancy or lymphoproliferative disease supports our reasoning.

The lowered activation threshold via the JAK-STAT pathway caused by the R840C mutation combined with insufficient control of activated T cells caused by the CTLA4 Y139C haploinsufficiency may also account for the high proportion of circulating 


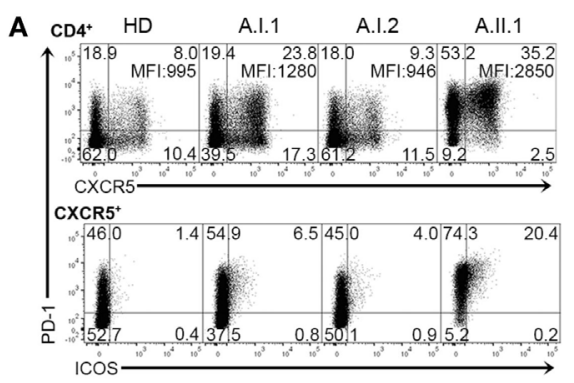

B

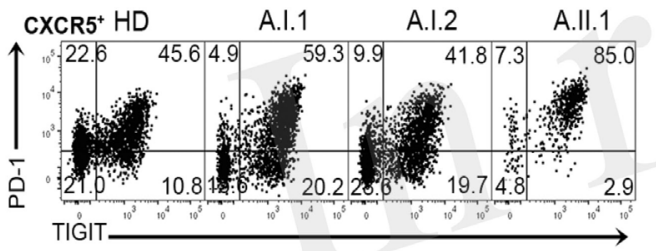

PD-1 $1^{+}$
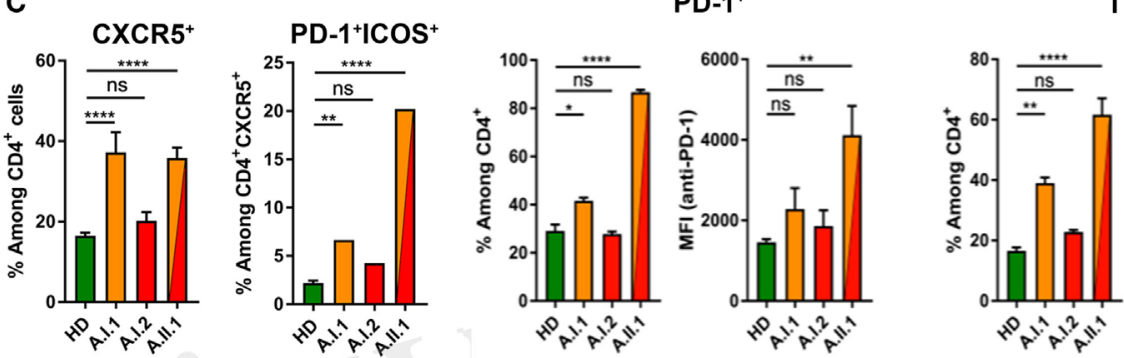

TIGIT+ $^{+}$

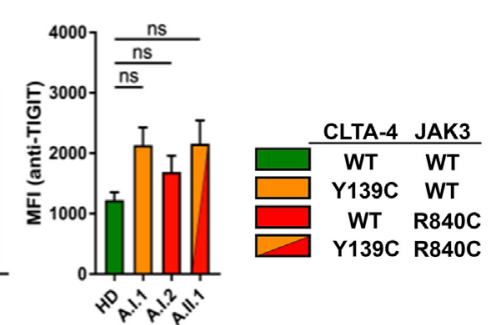

D

PD-1 ${ }^{+}$

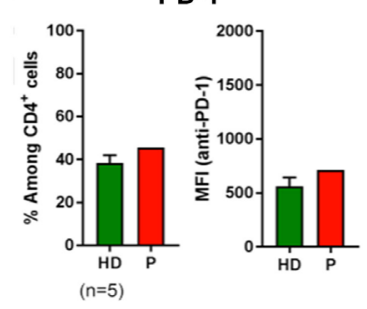

TIGIT $^{+}$
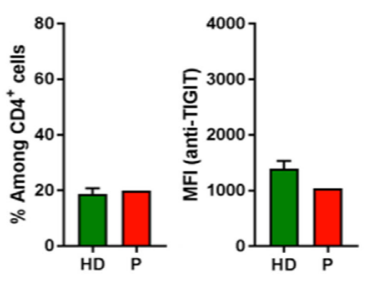

E

PD-1 ${ }^{+}$

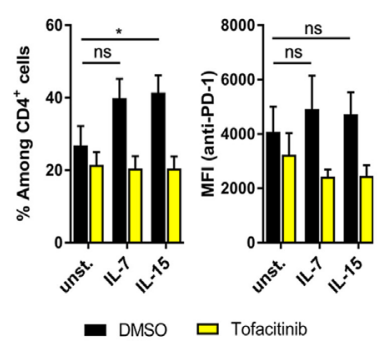

TIGIT $^{+}$

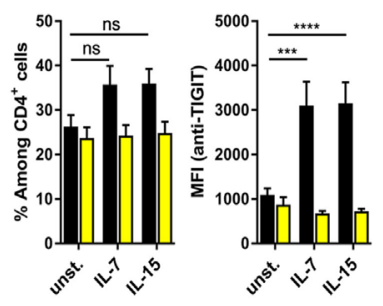

FIGURE 5 | PD-1 and TIGIT expression by $T_{\text {FH }}$ cells. (A) PD-1, CXCR5, and ICOS expression shown by representative flow cytometry plots of PBMCs gated on $\mathrm{CD}^{+}{ }^{+} \mathrm{CD} 4^{+}$from a healthy donor (HD) and members A.I.1, A.I.2, and A.Il.1 (patient) of family A. Numbers in quadrant corners show population frequencies, additional numbers in upper right corner (top) represent mean fluorescence intensity (MFI) of PD-1 expressed by CXCR5+PD-1+ cells. (B) Flow cytometry plots of PBMCs showing PD-1 and TIGIT expression by CXCR5 ${ }^{+} \mathrm{CD} 4^{+} T$ cells. (C) Left panels: frequency of PD- 1 and TIGIT expressing $\mathrm{CXCR}^{+}$and ICOS ${ }^{+} \mathrm{CD} 4^{+} \mathrm{T}$ cells of $\mathrm{HD}$ (green), A.I.1 (orange), A.I.2 (red), and A.ll.1 (red/orange). Middle panels: frequency of PD-1+ and of TIGIT+ CD4+ T cells and mean fluorescence intensity (MFI) of PD-1 and TIGIT expressed by CD4+ T cells of HD, A.I.1, A.I.2, and A.II.1 (D) PD-1 and TIGIT expression by an unrelated cytotoxic T lymphocyte antigen-4 (CTLA-4) haploinsufficiency patient with a heterozygous p.Y89X CTLA-4 mutation. (E) Frequency of PD-1 and TIGIT expressing CD4+ cells and expression levels of PD-1 and TIGIT determined by the MFI of PD-1 and TIGT expressed by CD4+ T cells treated for 5 days with or without (unst.) IL-7 and IL-15 in the presence or absence of the JAK inhibitor tofacitinib. Data in (C) represent mean \pm SEM of 26 different donors (HD, CXCR5', and PD-1+ICOS+) and two family visits, or mean \pm SEM of 4 (TIGIT) and 7 (PD-1) different HDs and 2 (TIGIT) and 3 (PD-1) family visits, in (D) the mean \pm SEM of five different HDs and the CTLA-4 p.Y89X patient, and in (E) show the mean \pm SEM of three experiments with six different HDs. ${ }^{\star \star \star \star} P \leq 0.0001 ;{ }^{\star \star \star} P<0.001 ;{ }^{\star \star} P<0.01 ;{ }^{\star} P \leq 0.05$. One-way (A,C) or two-way (D) ANOVA, Dunnett's multiple comparisons test.

$\mathrm{CD}^{+} \mathrm{PD}-1^{+} \mathrm{TIGIT}^{+} \mathrm{T}$ cells. This $\mathrm{T}$ cell population includes a significant fraction of circulating CXCR5 ${ }^{+} \mathrm{ICOS}^{+} \mathrm{PD}-1^{+} \mathrm{T}_{\mathrm{FH}}$ cells expressing very high levels of PD-1, which might be caused by the intrinsic kinase activity of the JAK3 R840C variant.

The skewing of the T cell compartment toward PD-1+TIGIT ${ }^{+}$ $\mathrm{T}_{\mathrm{FH}}$ cells might give rise to the highly enlarged germinal centers observed in the LN and the spleen. PD-1, in particular, is essential for a sustained GC reaction (31). In addition, we detected in the follicles a set of relevant markers like BCL-6, ICOS, IRF-4, and IgG, which are indicative of GC activity. In spite of the enlarged $\mathrm{T}_{\mathrm{FH}}$ cell compartment, circulating switched memory $\mathrm{B}$ cells were missing and the output of $\mathrm{CD} 138^{+}$plasma cells from germinal centers was found to be severely impaired leading to hypogammaglobulinemia. This paradoxical immunophenotype of an expanded $\mathrm{T}_{\mathrm{FH}}$ cell compartment with large follicles but defective late $B$ cell differentiation has similarities to the impaired B cell immunity observed in HIV-infected individuals (38). In HIVinfected individuals, impaired vaccination responses in the presence of large lymphoid follicles in the LNs has been attributed to the reduction in IL-21 secretion by $\mathrm{T}_{\mathrm{FH}}$ cells caused by interactions between PD-L1 and PD-1, expressed by germinal center B cells and by $\mathrm{T}_{\mathrm{FH}}$ cells, respectively. Our data fit well into this scenario, because in vitro activated circulating $\mathrm{T}_{\mathrm{FH}}$ cells of A.II.1 produced less IL-21 and IL-4 than $\mathrm{T}_{\mathrm{FH}}$ cells from healthy controls. In contrast 
to the disturbed $\mathrm{T}_{\mathrm{H}} 2$ activity, IFN- $\gamma$ and IL-17 production was normal. Since IL-21 and IL-4 are key GC cytokines driving B cell proliferation and differentiation into plasma cells $(29,30)$, the
PD- ${ }^{+}$TIGIT ${ }^{+}$IL- $21^{\text {lo }}$ IL- $4^{\text {lo }} \mathrm{T}_{\mathrm{FH}}$ cells may not provide sufficient levels of cytokines to support the development of GC B cells into normal plasma cells. In addition to PD-1, the co-expression of the

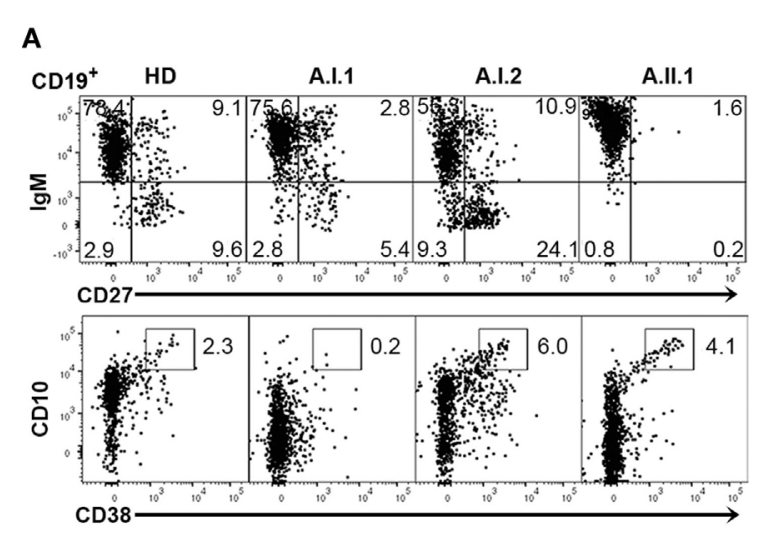

C

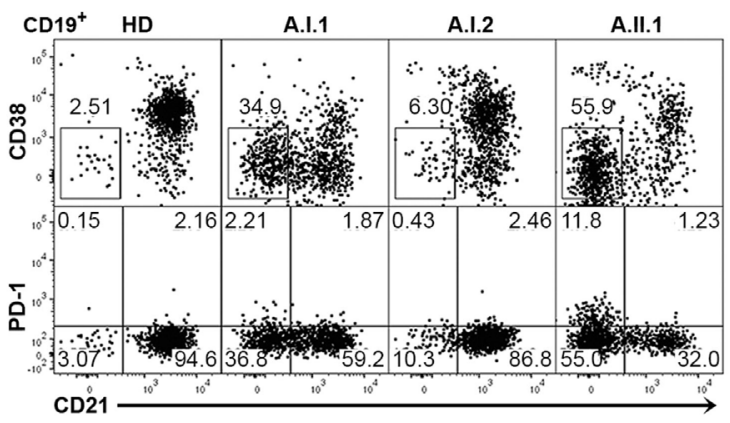

B

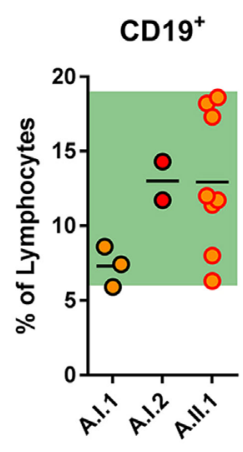

D

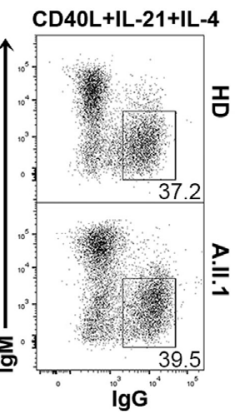

B cells

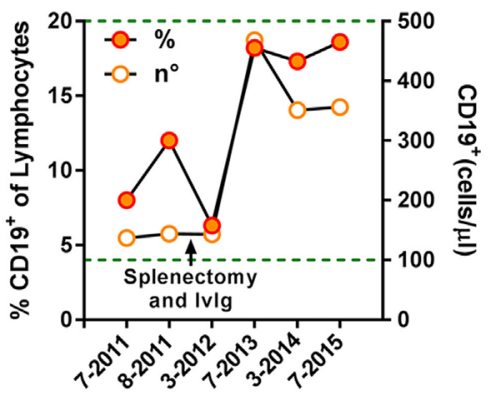

E

$\lg M$

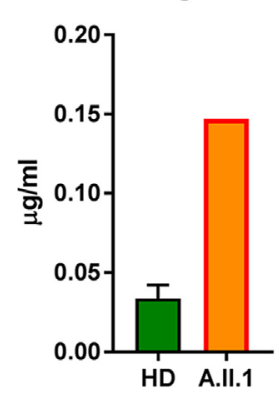

$\lg G$

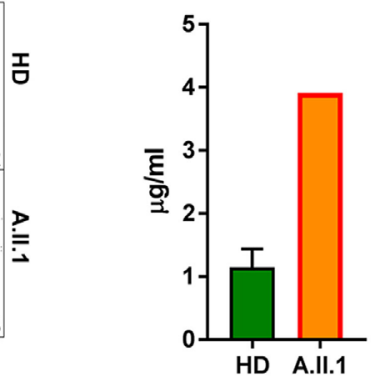

$\mathbf{F}$

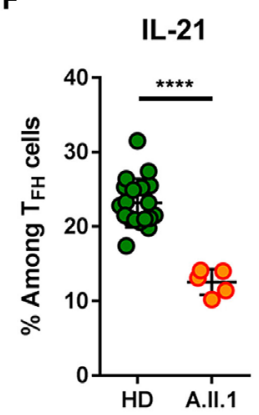

IL-4

IFN- $\gamma$

IL-17A

IFN- $\gamma$

TNF- $\alpha$
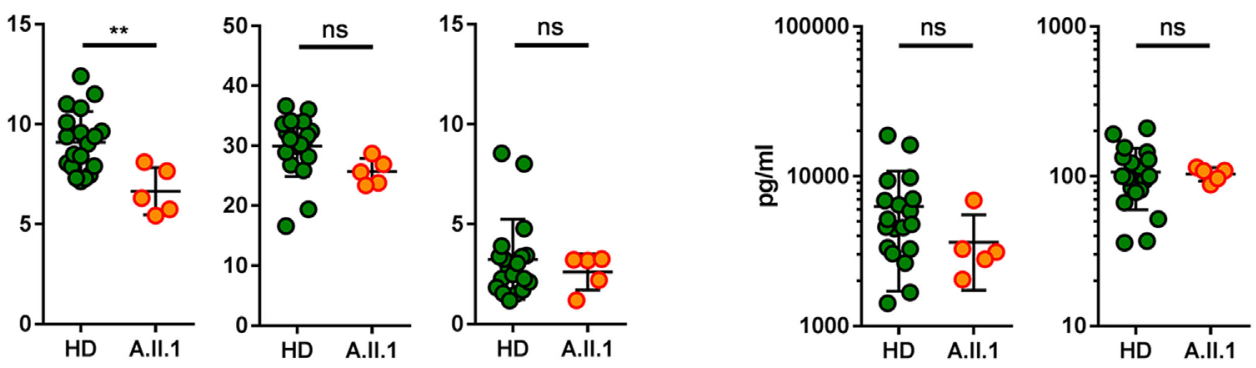

IL-10

IL-4

IL-6

IL-2

IL-8

IL-13
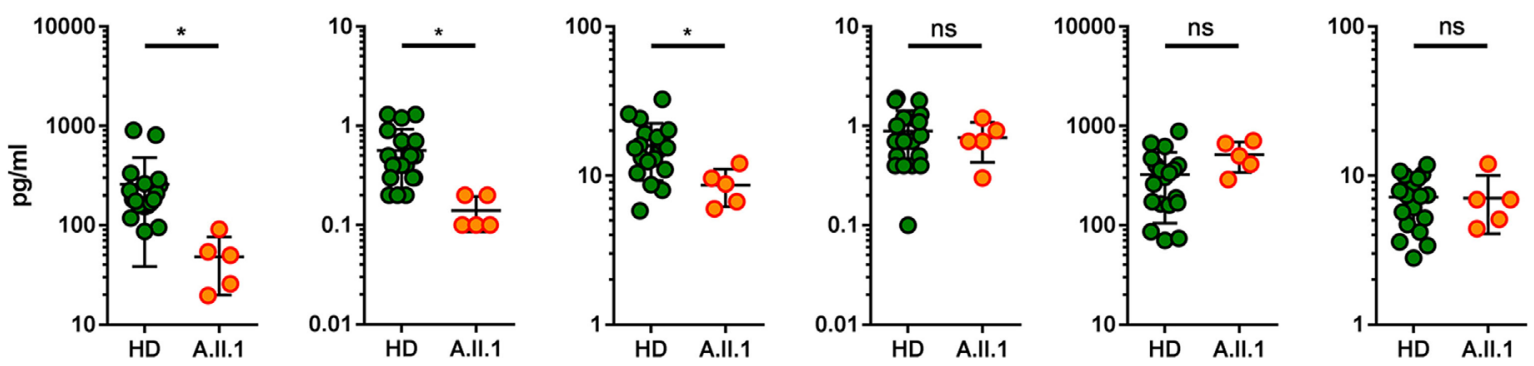

FIGURE 6 | Continued 
FIGURE 6 | B cell phenotype, in vitro differentiation of B cells and impaired function of $T_{F H}$ cells. (A) Representative flow cytometry plots of PBMCs stained for CD19, CD10, CD27, CD38, and lgM. The plots display CD19+ lymphocytes and show the population frequencies of transitional (CD10+CD38++), naïve $\left(\mathrm{lgM}^{+} \mathrm{CD} 27^{-}\right)$, marginal zone $\left(\operatorname{lgM}{ }^{+} \mathrm{CD} 27^{+}\right)$, or switched memory (IgM-CD27+) B cell subsets. (B) Frequencies of CD19+ B cell from family members (left panel) and relative and absolute numbers of patient $B$ cells within a 4-year period (right panel). Horizontal lines represent mean values. Each dot represents the mean of replicate assays and repeated experiments on different visits. Green background (left panel) and dotted line indicate normal range of B cell frequencies and of absolute numbers.(C) Representative flow cytometry plots of CD19+ lymphocytes from healthy donor (HD) and family members A.I.1, A.I.2, and A.II.1 (patient)

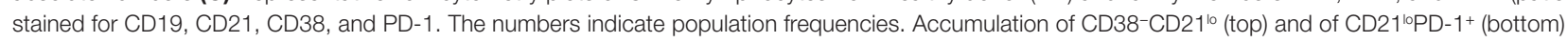
$B$ cells in the patient (A.II.1) and the father (A.I.1) compared to a representative HD. (D) Frequencies of class-switched lgG ${ }^{+}$B cells developing in vitro from $\mathrm{IgM}^{+} \lg \mathrm{G}^{-} \mathrm{B}$ cells activated with CD4OL, IL-4, and IL-21 for 5 days. (E) IgM and IgG concentrations in the supernatants of CD19+CD27-IgG-IgA- B cells activated in vitro for 6 days with CD40L, IL-4, and IL-21. (F) Left panels: frequency of IL-21, IL-4, IFN- $\gamma$, and IL-17A expressing CD4+ T cells after coculture with allogeneic $\mathrm{CD}^{19}{ }^{+} \mathrm{CD}_{27-}{ }^{-} \mathrm{gG}{ }^{-} \operatorname{lgA} \mathrm{A}^{-}$sorted B cells and re-stimulation with phorbol 12-myristate 13-acetate and ionomycin. Right and lower panels: cytokine concentrations in the supernatants of $\mathrm{CD}^{+}{ }^{+} \mathrm{CD} 45 \mathrm{RA}{ }^{-} \mathrm{CXCR} 5^{+}$sorted $\mathrm{T}_{\mathrm{FH}}$ cells cultivated with $\mathrm{CD} 19^{+} \mathrm{CD} 27^{-}-\lg \mathrm{G}^{-} \lg \mathrm{A}^{-}$stimulator $\mathrm{B}$ cells from blood of five $\mathrm{HD}$ and from the patient. Data are representative for $(\mathbf{A}, \mathbf{C}, \mathbf{D})$ or show mean \pm SEM (E) of three different HDs and the patient (A.II.1) or mean \pm SEM (F) of different $B$ and T cell coculture combinations from five HD and the patient. Significant differences (two-tailed, unpaired $t$-test) between control subjects and patient are indicated. ${ }^{\star} P=0.05$; ${ }^{\star \star} P=0.01,{ }^{\star \star \star \star} P<0.0001$.

negative regulator TIGIT by $\mathrm{CD} 4^{+} \mathrm{PD}-1^{+} \mathrm{T}$ cells may contribute to the inhibition of $\mathrm{T}$ cell function, as reported for $\mathrm{T}$ cells treated with agonistic anti-TIGIT antibodies (39).

Therefore, the development of dysfunctional $\mathrm{T}_{\mathrm{FH}}$ cells offers an explanation for the almost complete absence of plasma cells in the LN and hypogammaglobulinemia despite high GC activity in our patient.

In summary, we report here that a rare genetic variant of JAK3 may change a clinically unremarkable CTLA-4 haploinsufficiency to an overt CTLA-4 syndrome. However, the combination of mutations activating JAK3 with CTLA4-inactivating mutations seems to be very rare since the screening of 52 patients with CTLA-4 haploinsufficiency did not reveal another case with a missense mutation in the JAK3 gene. Therefore, also other factors including genetic modifiers can determine the clinical penetrance of mutations in the CTLA-4 gene.

Other clinically related syndromes may result from the combination of hypomorphic/hypermorphic, heterozygous mutations, in genes regulating the immune system. For example, incomplete penetrance, exemplified by a significant fraction of non-symptomatic carriers, has been described for genetic defects associated with lymphoproliferation and lymphadenopathy, such as activated PI3K $\delta$ syndrome (APDS) (40-43) or FAS-associated autoimmune lymphoproliferative syndrome (ALPS-FAS) (44). In general, hyperimmunity and lymphoid hyperplasia or autoimmunity is not uncommon in patients with primary antibody deficiency $(45,46)$, and an aberrant $\mathrm{T}_{\mathrm{FH}}$ phenotype similar to the one we describe here may underlie this paradox. Our findings may stimulate the search for combinations of immune-modulating gene variants in CVID patients to identify pathogenic molecular and cellular pathways and to potentially enable individualized and targeted therapy.

\section{ETHICS STATEMENT}

This study was approved and carried out in accordance with the recommendations of the Ethics Committee of the University of Freiburg; with written informed consent from all subjects. All subjects gave written informed consent in accordance with the
Declaration of Helsinki. The protocol was approved by the Ethics Commission of the University of Freiburg.

\section{AUTHOR CONTRIBUTIONS}

HS, MS, ET, HG, and HE designed experiments. HS performed most experiments and analyzed data. MS, and ES contributed human samples and performed DNA sequence analyses. VC, MS, and ES performed experiments. EO performed whole exome sequencing and $\mathrm{MB}, \mathrm{BL}$, and FY contributed bioinformatics analysis of exome data. EV contributed protein modeling. AG, AS, ET, HG, and HE provided reagents and intellectual input. HS, HG, and HE wrote the manuscript with input from AS, MS, and ET All authors discussed and revised the manuscript.

\section{ACKNOWLEDGMENTS}

We thank the patient and his family. We are very grateful to Dr. M. J. Lenardo and Dr. Y. Zhang for sharing with us their database information on mutations in the CTLA4 and JAK3 genes. We thank, Dr. S. Popp, B. Fischer, C. Tschopp, M. I. Clay, S. Richards, M. K. Kurz, P. Müller-Sänger, and B. Kerins for expert technical assistance. We would like to thank Dr. Maria Ioannou for providing samples of lymph nodes and spleen of the patient for the immunohistochemical assays. The authors would like to thank the Exome Aggregation Consortium and the groups that provided exome variant data for comparison. A full list of contributing groups can be found at http://exac.broadinstitute.org/about.

\section{FUNDING}

This work was supported by a grant from Novartis.

\section{SUPPLEMENTARY MATERIAL}

The Supplementary Material for this article can be found online at http://www.frontiersin.org/articles/10.3389/fimmu.2017.01824/ full\#supplementary-material. 


\section{REFERENCES}

1. Cunningham-Rundles C. How I treat common variable immune deficiency. Blood (2010) 116:7-15. doi:10.1182/blood-2010-01-254417

2. Ameratunga R, Brewerton M, Slade C, Jordan A, Gillis D, Steele R, et al. Comparison of diagnostic criteria for common variable immunodeficiency disorder. Front Immunol (2014) 5:415. doi:10.3389/fimmu.2014.00415

3. Bogaert DJA, Dullaers M, Lambrecht BN, Vermaelen KY, De Baere E, Haerynck F. Genes associated with common variable immunodeficiency: one diagnosis to rule them all? J Med Genet (2016) 53:575-90. doi:10.1136/ jmedgenet-2015-103690

4. Grimbacher B, Warnatz K, Yong PFK, Korganow AS, Peter HH. The crossroads of autoimmunity and immunodeficiency: lessons from polygenic traits and monogenic defects. J Allergy Clin Immunol (2016) 137:3-17. doi:10.1016/j. jaci.2015.11.004

5. Lee S, Moon JS, Lee C-R, Kim H-E, Baek S-M, Hwang S, et al. Abatacept alleviates severe autoimmune symptoms in a patient carrying a de novo variant in CTLA-4. J Allergy Clin Immunol (2016) 137:327-30. doi:10.1016/j. jaci.2015.08.036

6. Kuehn HS, Ouyang W, Lo B, Deenick EK, Niemela JE, Avery DT, et al. Immune dysregulation in human subjects with heterozygous germline mutations in CTLA4. Science (2014) 345:1623-7. doi:10.1126/science.1255904

7. Schubert D, Bode C, Kenefeck R, Hou TZ, Wing JB, Kennedy A, et al. Autosomal dominant immune dysregulation syndrome in humans with CTLA4 mutations. Nat Med (2014) 20:1410-6. doi:10.1038/nm.3746

8. Teft WA, Kirchhof MG, Madrenas J. A molecular perspective of CTLA-4 function. Annu Rev Immunol (2006) 24:65-97. doi:10.1146/annurev. immunol.24.021605.090535

9. Waterhouse P, Penninger JM, Timms E, Wakeham A, Shahinian A, Lee KP, et al. Lymphoproliferative disorders with early lethality in mice deficient in CTLA-4. Science (1995) 270:985-8. doi:10.1126/science.270.5238.985

10. Rochman Y, Spolski R, Leonard WJ. New insights into the regulation of T cells by gamma(c) family cytokines. Nat Rev Immunol (2009) 9:480-90. doi:10.1038/nri2580

11. Lupardus PJ, Ultsch M, Wallweber H, Bir Kohli P, Johnson AR, Eigenbrot C. Structure of the pseudokinase-kinase domains from protein kinase TYK2 reveals a mechanism for Janus kinase (JAK) autoinhibition. Proc Natl Acad Sci U S A (2014) 111:8025-30. doi:10.1073/pnas.1401180111

12. Cattaneo F, Recher M, Masneri S, Baxi SN, Fiorini C, Antonelli F, et al. Hypomorphic Janus kinase 3 mutations result in a spectrum of immune defects, including partial maternal T-cell engraftment. J Allergy Clin Immunol (2013) 131:1136-45. doi:10.1016/j.jaci.2012.12.667

13. Casanova JL, Holland SM, Notarangelo LD. Inborn errors of human JAKs and STATs. Immunity (2012) 36:515-28. doi:10.1016/j.immuni.2012.03.016

14. Sic H, Kraus H, Madl J, Flittner K, von Münchow AL, Pieper K, et al. Sphingosine-1-phosphate receptors control B-cell migration through signaling components associated with primary immunodeficiencies, chronic lymphocytic leukemia, and multiple sclerosis. J Allergy Clin Immunol (2014) 134:420-8.e15. doi:10.1016/j.jaci.2014.01.037

15. Smulski CR, Kury P, Lea M, Rizzi M, Schneider P, Smulski CR, et al. BAFFand TACI-dependent processing of BAFFR by ADAM proteases regulates the survival of B cells article BAFF- and TACI-dependent processing of BAFFR by ADAM proteases regulates the survival of B cells. Cell Rep (2017) 18:2189-202. doi:10.1016/j.celrep.2017.02.005

16. Pieper K, Rizzi M, Speletas M, Smulski CR, Sic H, Kraus H, et al. A common single nucleotide polymorphism impairs B-cell activating factor receptor's multimerization, contributing to common variable immunodeficiency. J Allergy Clin Immunol (2014) 133:1222-5.e10. doi:10.1016/j.jaci.2013.11.021

17. Haan C, Rolvering C, Raulf F, Kapp M, Drückes P, Thoma G, et al. Jak1 has a dominant role over Jak3 in signal transduction through $\gamma \mathrm{c}$-containing cytokine receptors. Chem Biol (2011) 18:314-23. doi:10.1016/j.chembiol.2011.01.012

18. Stamper CC, Zhang Y, Tobin JF, Erbe DV, Ikemizu S, Davis SJ, et al. Crystal structure of the B7-1/CTLA-4 complex that inhibits human immune responses. Nature (2001) 410:608-11. doi:10.1038/35069118

19. Peach RJ, Bajorath J, Brady W, Leytze G, Greene J, Naemura J, et al. Complementarity determining region 1 (CDR1)- and CDR3-analogous regions in CTLA-4 and CD28 determine the binding to B7-1. J Exp Med (1994) 180:2049-58. doi:10.1084/jem.180.6.2049
20. Morton PA, Fu XT, Stewart JA, Giacoletto KS, White SL, Leysath CE, et al Differential effects of CTLA-4 substitutions on the binding of human CD80 (B7-1) and CD86 (B7-2). J Immunol (1996) 156:1047-54.

21. Hou TZ, Verma N, Wanders J, Kennedy A, Soskic B, Janman D, et al. Identifying functional defects in patients with immune dysregulation due to LRBA and CTLA-4 mutations. Blood (2017) 129:1458-69. doi:10.1182/blood2016-10-745174.functionally

22. ExAC Browser. (2017). Available from: http://exac.broadinstitute.org/ variant/19-17943490-G-A

23. Lek M, Karczewski K, Minikel E, Samocha K, Banks E, Fennell T, et al. Analysis of protein-coding genetic variation in 60,706 humans. Nature (2016) 536(7616):285-91. doi:10.1038/nature19057

24. Chrencik JE, Patny A, Leung IK, Korniski B, Emmons TL, Hall T, et al. Structural and thermodynamic characterization of the TYK2 and JAK3 kinase domains in complex with CP-690550 and CMP-6. J Mol Biol (2010) 400:413-33. doi:10.1016/j.jmb.2010.05.020

25. Godefroy E, Zhong H, Pham P, Friedman D, Yazdanbakhsh K. TIGIT-positive circulating follicular helper T cells display robust B-cell help functions: potential role in sickle cell alloimmunization. Haematologica (2015) 100:1415-25. doi:10.3324/haematol.2015.132738

26. Rakhmanov M, Keller B, Gutenberger S, Foerster C, Hoenig M, Driessen G, et al. Circulating CD21low B cells in common variable immunodeficiency resemble tissue homing, innate-like B cells. Proc Natl Acad Sci U S A (2009) 106:13451-6. doi:10.1073/pnas.0901984106

27. Moir S, Malaspina A, Ogwaro KM, Donoghue ET, Hallahan CW, Ehler LA, et al. HIV-1 induces phenotypic and functional perturbations of B cells in chronically infected individuals. Proc Natl Acad Sci U S A (2001) 98:10362-7. doi:10.1073/pnas.181347898

28. Phetsouphanh C, Xu Y, Zaunders J. CD4 T cells mediate both positive and negative regulation of the immune response to HIV infection: complex role of $\mathrm{T}$ follicular helper cells and regulatory $\mathrm{T}$ cells in pathogenesis. Front Immunol (2015) 5:681. doi:10.3389/fimmu.2014.00681

29. Kräutler NJ, Suan D, Butt D, Bourne K, Hermes JR, Chan TD, et al. Differentiation of germinal center B cells into plasma cells is initiated by high-affinity antigen and completed by Tfh cells. J Exp Med (2017) 214:125967. doi:10.1084/jem.20161533

30. Moens L, Tangye SG. Cytokine-mediated regulation of plasma cell generation: IL-21 takes center stage. Front Immunol (2014) 5:65. doi:10.3389/ fimmu.2014.00065

31. Crotty S. Follicular helper CD4 T cells (TFH). Annu Rev Immunol (2011) 29:621-63. doi:10.1146/annurev-immunol-031210-101400

32. Verma N, Burns SO, Walker LS, Sansom DM. Immune deficiency and autoimmunity in patients with CTLA-4 mutations. Clin Exp Immunol (2017) 190(1):1-7. doi:10.1111/cei.12997

33. Lo B, Fritz JM, Su HC, Uzel G, Jordan MB, Lenardo MJ. CHAI and LATAIE: new genetic diseases of CTLA-4 checkpoint insufficiency. Blood (2017) 128:1037-42. doi:10.1182/blood-2016-04-712612

34. Lenardo M, Lo B, Lucas CL. Genomics of immune diseases and new therapies. Annu Rev Immunol (2016) 34:121-49. doi:10.1146/annurevimmunol-041015-055620

35. Springuel L, Hornakova T, Losdyck E, Lambert F, Leroy E, Constantinescu SN, et al. Cooperating JAK1 and JAK3 mutants increase resistance to JAK inhibitors. Blood (2014) 124:3924-31. doi:10.1182/blood-2014-05-576652

36. Marty C, Saint-Martin C, Pecquet C, Grosjean S, Saliba J, Mouton C, et al. Germ-line JAK2 mutations in the kinase domain are responsible for hereditary thrombocytosis and are resistant to JAK2 and HSP90 inhibitors. Blood (2014) 123:1372-83. doi:10.1182/blood-2013-05-504555

37. Walters DK, Mercher T, Gu TL, O’Hare T, Tyner JW, Loriaux M, et al. Activating alleles of JAK3 in acute megakaryoblastic leukemia. Cancer Cell (2006) 10:65-75. doi:10.1016/j.ccr.2006.06.002

38. Cubas RA, Mudd JC, Savoye A-L, Perreau M, van Grevenynghe J, Metcalf T, et al. Inadequate $\mathrm{T}$ follicular cell help impairs B cell immunity during HIV infection. Nat Med (2013) 19:494-9. doi:10.1038/nm.3109

39. Lozano E, Dominguez-Villar M, Kuchroo V, Hafler DA. The TIGIT/CD226 axis regulates human $\mathrm{T}$ cell function. J Immunol (2012) 188:3869-75. doi:10.4049/jimmunol.1103627

40. Angulo I, Vadas O, Garçon F, Banham-Hall E, Plagnol V, Leahy TR, et al. Phosphoinositide 3-kinase $\delta$ gene mutation predisposes to respiratory 
infection and airway damage. Science (2013) 342:866-71. doi:10.1126/ science. 1243292

41. Conley ME, Dobbs AK, Quintana AM, Bosompem A, Wang Y-D, CoustanSmith E, et al. Agammaglobulinemia and absent B lineage cells in a patient lacking the p85 subunit of PI3K. J Exp Med (2012) 209:463-70. doi:10.1084/ jem. 20112533

42. Lucas CL, Zhang Y, Venida A, Wang Y, Hughes J, McElwee J, et al. Heterozygous splice mutation in PIK3R1 causes human immunodeficiency with lymphoproliferation due to dominant activation of PI3K. J Exp Med (2014) 211:2537-47. doi:10.1084/jem.20141759

43. Lucas CL, Kuehn HS, Zhao F, Niemela JE, Deenick EK, Palendira U, et al. Dominant-activating germline mutations in the gene encoding the PI(3) $\mathrm{K}$ catalytic subunit p1108 result in T cell senescence and human immunodeficiency. Nat Immunol (2014) 15:88-97. doi:10.1038/ni.2771

44. Price S, Shaw PA, Seitz A, Joshi G, Davis J, Niemela JE, et al. Natural history of autoimmune lymphoproliferative syndrome associated with FAS gene mutations. Blood (2014) 123:1989-99. doi:10.1182/blood-2013-10-535393

45. Warnatz K, Wehr C, Dräger R, Schmidt S, Eibel H, Schlesier M, et al. Expansion of CD19(hi)CD21(lo/neg) B cells in common variable immunodeficiency
(CVID) patients with autoimmune cytopenia. Immunobiology (2002) 206:502-13. doi:10.1078/0171-2985-00198

46. Unger S, Seidl M, Schmitt-Graeff A, Böhm J, Schrenk K, Wehr C, et al. Illdefined germinal centers and severely reduced plasma cells are histological hallmarks of lymphadenopathy in patients with common variable immunodeficiency. J Clin Immunol (2014) 34:615-26. doi:10.1007/s10875-014-0052-1

Conflict of Interest Statement: HS, VC, MB, FY, EO, EV, AS, ET, and HG are employees of Novartis Pharma AG, Basel, Switzerland. All other authors declare no potential conflict of interest.

Copyright $\odot 2017$ Sic, Speletas, Cornacchione, Seidl, Beibel, Linghu, Yang, Sevdali, Germenis, Oakeley, Vangrevelinghe, Sailer, Traggiai, Gram and Eibel. This is an open-access article distributed under the terms of the Creative Commons Attribution License (CC BY). The use, distribution or reproduction in other forums is permitted, provided the original author(s) or licensor are credited and that the original publication in this journal is cited, in accordance with accepted academic practice. No use, distribution or reproduction is permitted which does not comply with these terms. 